\title{
Recovery of methamphetamine associated cardiomyopathy predicted by late gadolinium enhanced cardiovascular magnetic
} resonance

\author{
Javier E Lopez¹, Khung Yeo1, Gary Caputo², Michael Buonocore² and \\ Saul Schaefer*1
}

\begin{abstract}
Address: ${ }^{1}$ Department of Internal Medicine, Division of Cardiovascular Medicine, One Shields Avenue, Davis CA 95618, USA and ${ }^{2}$ Department of Radiology, University of California Davis Medical Center, 2315 Stockton Boulevard, Sacramento, CA 95817, USA

Email: Javier E Lopez - javier.lopez@ucdmc.ucdavis.edu; Khung Yeo - yeo_kk@yahoo.com; Gary Caputo - gary.caputo@ucdmc.ucdavis.edu; Michael Buonocore - mhbuonocore@ucdavis.edu; Saul Schaefer* - sschaefer@ucdavis.edu

* Corresponding author
\end{abstract}

Published: II November 2009

Journal of Cardiovascular Magnetic Resonance 2009, I I:46 doi:I0.1 I86/1532-429X-I I-46

This article is available from: http://www.jcmr-online.com/content/I I/I/46

(C) 2009 Lopez et al; licensee BioMed Central Ltd.

This is an Open Access article distributed under the terms of the Creative Commons Attribution License (http://creativecommons.org/licenses/by/2.0), which permits unrestricted use, distribution, and reproduction in any medium, provided the original work is properly cited.
Received: 19 May 2009

Accepted: II November 2009

\begin{abstract}
Methamphetamine is known to cause a cardiomyopathy which may be reversible with appropriate medical therapy and cessation of use. Late gadolinium enhancement cardiovascular magnetic resonance (CMR) has been shown to identify fibrosis in ischemic and non-ischemic cardiomyopathies. We present a case of severe methamphetamine-associated cardiomyopathy in which cardiac function recovered after 6 months. Evaluation by CMR using late gadolinium enhancement was notable for an absence of enhancement, suggesting an absence of irreversible myocyte injury and a good prognosis. CMR may be useful to predict recovery in toxin-associated non-ischemic cardiomyopathies.
\end{abstract}

\section{Background}

Methamphetamine is a synthetic amine commonly used as a recreational drug because of its stimulant effects. Its use has increased nationwide [1] and recent reports suggest that methamphetamine use is present in at least 5\% of all patients presenting to the emergency room with heart failure [2] and $40 \%$ of patients under the age of 45 admitted to the hospital with cardiomyopathy [3]. Chronic use has also been associated with the development of chronic coronary disease $[4,5]$ as well as cardiomyopathy $[3,6]$.

Recovery of left ventricular dysfunction in patients with methamphetamine-induced cardiomyopathy has been described [7-9]. However, since the effects of metham- phetamine can include myocyte hypertrophy [10] and fibrosis $[11,12]$, both relatively irreversible processes, it is likely that some patients will not recover left ventricular function with either appropriate medical therapy or abstinence from methamphetamine.

Cardiovascular magnetic resonance (CMR) with late gadolinium enhancement (LGE) has been show to identify myocardial fibrosis in ischemic and non-ischemic cardiomyopathies $[13,14]$ and provide prognostic information about cardiac recovery in these disease processes [15]. LGE has not, to our knowledge, been used to evaluate fibrosis and predict recovery in methamphetamine-associated cardiomyopathy. 
We herein report a case of recovery of left ventricular function in a patient with methamphetamine-associated cardiomyopathy demonstrated using LGE.

\section{Case report}

A 44 year old woman presented to the emergency department with 3 days of peripheral edema, paroxysmal nocturnal dyspnea, and dyspnea on exertion. She denied chest pain, fever, rashes and/or recent viral illnesses. She had no recent exposure to ill contacts or foreign travel. Her review of systems was otherwise unremarkable. Her past medical history consisted of pregnancy related hypertension 4 years prior that required no therapy after delivery. Her social history consisted of 15 years of inhaled methamphetamine and tobacco use. She denied alcohol or other street drug use. She was taking no medications at time of presentation. Her surgical history consisted of one normal child delivery 4 years prior, a tubal ligation and tonsillectomy. Physical examination revealed a blood pressure of $159 / 109 \mathrm{mmHg}$, pulse of $109 \mathrm{bpm}$, and a temperature of $36.3^{\circ} \mathrm{C}$. Her arterial $\mathrm{O}_{2}$ saturation was $99 \%$ on room air. Cardiac examination revealed a JVP of $12 \mathrm{~cm}$ and a 3/6 holosystolic murmur best heard at the apex without respiratory variation. She had no organomegaly or ascites and her extremities had $2+$ pitting edema. Her laboratory data demonstrated a sodium of $138 \mathrm{mEq} / \mathrm{L}$, creatinine of 1.1 , and serum troponin of $0.11(\mathrm{ng} / \mathrm{ml})$. A chest X-ray showed cardiomegaly, an electrocardiogram showed left ventricular hypertrophy and ST-T wave abnormalities. Two-dimensional echocardiography showed reduced systolic function (Figure 1).

After informed consent, she underwent LGE using standard techniques [16]. Briefly, images were acquired on a Siemens 3T Trio MR system using a 4 element cardiac array coil. After localization scans, CINE sequences were run in three planes for assessment of wall motion and ejection fraction. The contrast agent (gadolinium-DTPA, $0.2 \mathrm{ml} / \mathrm{Kg}$ ) was injected and a set of inversion recovery (IR) gradient recalled echo (GRE) sequences was run with different TI values starting $5 \mathrm{~min}$ after injection. Following determination of the optimal TI value, IR-GRE "delayed enhancement" images were acquired in the short axis, vertical long axis and horizontal long axis orientations 10-20 minutes after the injection of the contrast agents. One to eight slice locations were acquired for each orientation. Images were analyzed in duplicate using a Leonardo workstation (Siemens Medical Solutions, Erlangen, Germany). Ejection fraction and left ventricular mass were calculated by computer-assisted endocardial border definition of end-diastolic and end-systolic frames. The presence of gadolinium enhancement was defined as pixel intensity in the myocardium $>3 \times$ background [16].

Echocardiography and CMR both showed a reduced ejection fraction, calculated at $37 \%$ using quantitative analy-

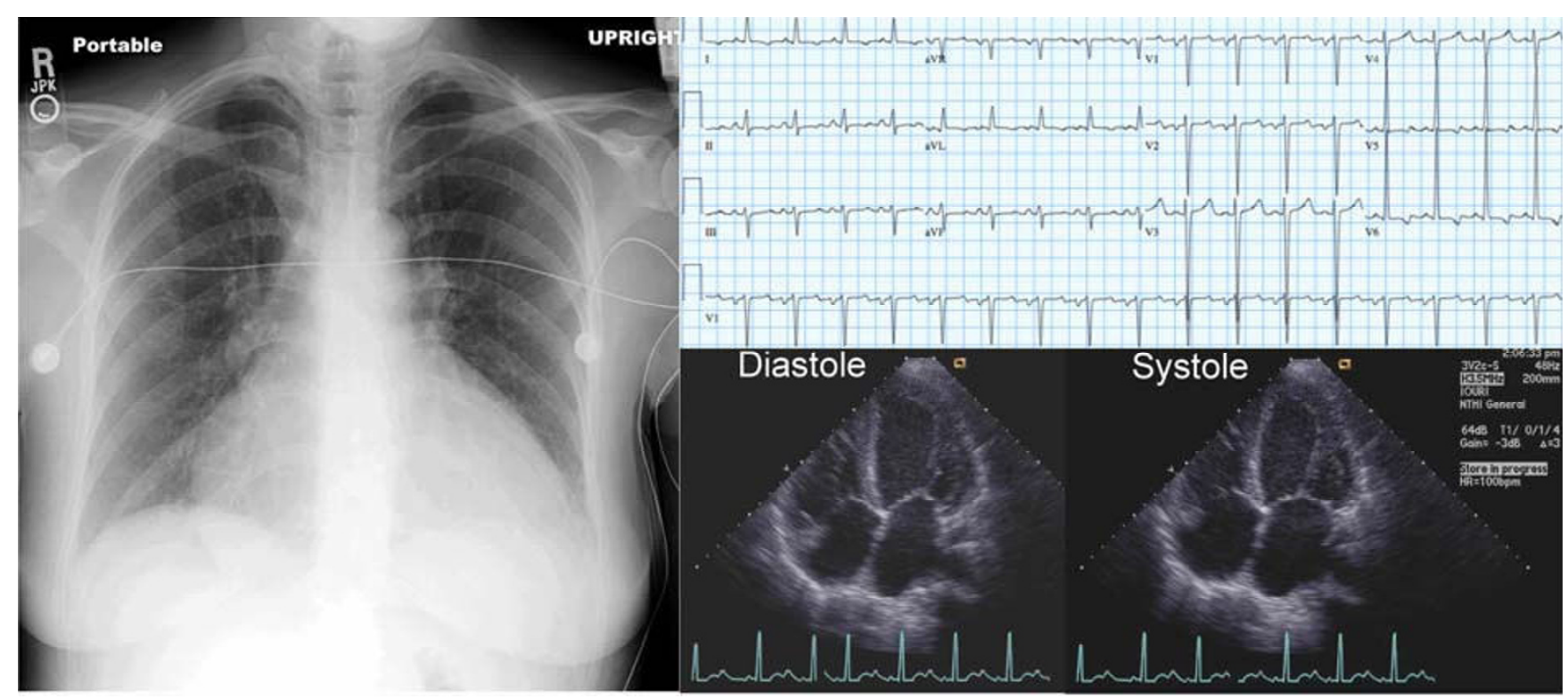

\section{Figure I}

Chest X-ray, electrocardiogram, and 2-D echocardiograms of the patient on initial evaluation. These examinations demonstrated cardiomegaly, left ventricular hypertrophy with ST-T wave changes, and decreased left ventricular systolic function. 

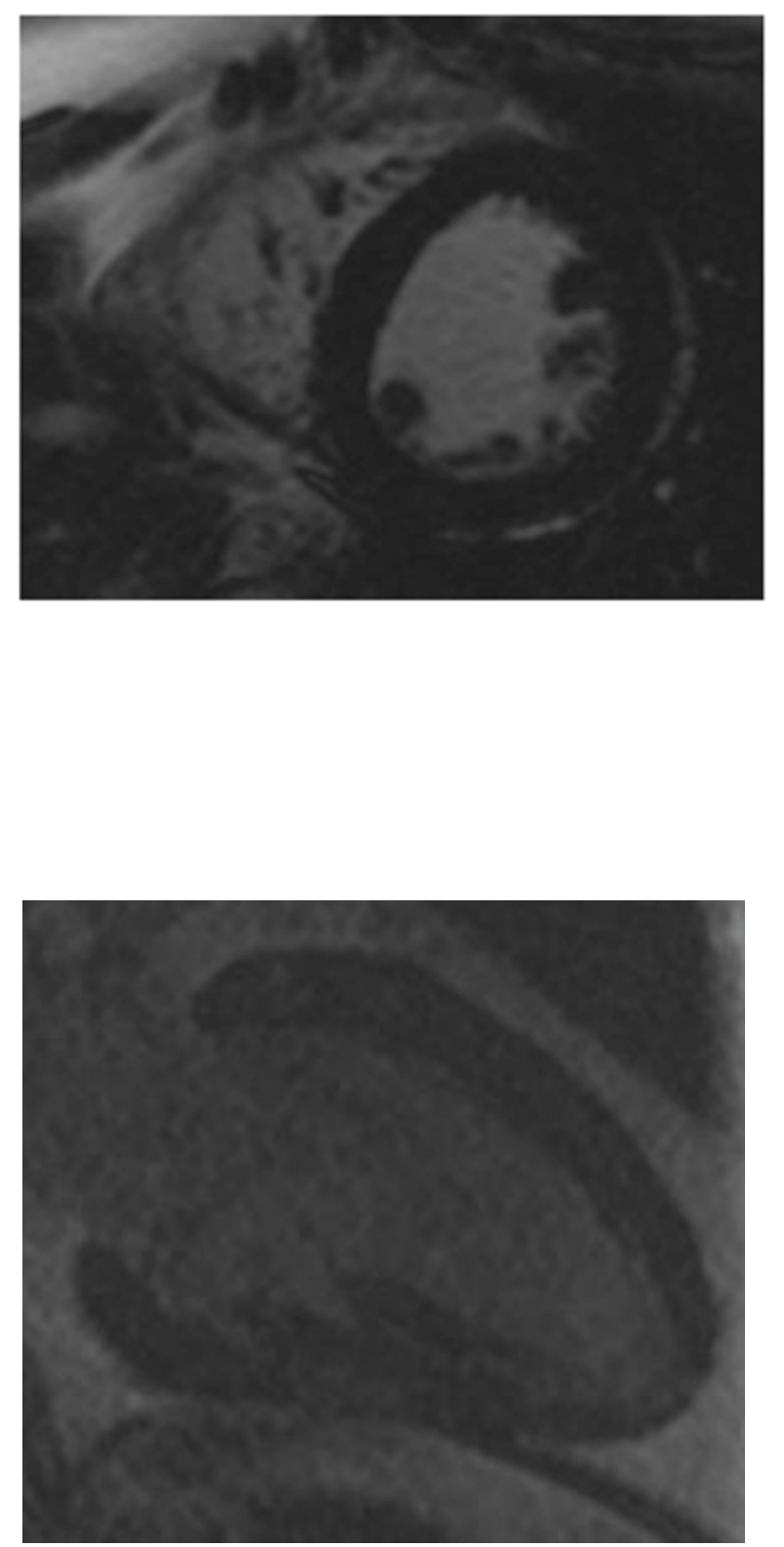

\section{Figure 2}

Late gadolinium enhancement short-axis and vertical long axis images. There was no myocardial enhancement (black).

sis of GRE images. There was no LGE (Figure 2). She was placed on medical therapy including a beta-blockers and an angiotensin converting enzyme inhibitor and was advised to abstain from methamphetamine use.

Following 6 months of medical therapy and decreased use of methamphetamine, she again was evaluated for signs and symptoms of heart failure. At this time, she had improved clinically to functional class I. Echocardiography showed a normal ejection fraction and quantitative CMR showed an ejection fraction of $64 \%$ (Figure 3). Left ventricular mass changed from 234 to 185 grams.

\section{Discussion}

This patient illustrates the potential use of LGE as a tool to predict whether patients with methamphetamine-associated cardiomyopathy can recover left ventricular function with appropriate medical therapy. In this instance, the absence of gadolinium enhancement was consistent with an absence of macroscopic regions of fibrosis and hence, no irreversible myocardial injury.

Methamphetamine is a sympathomimetic agent that mediates its cardiovascular effects through excessive release of norepinephrine and blockade of reuptake at the sympathetic synaptic receptors [17]. This sympathetic stimulation can cause either acute ventricular dysfunction, such as seen in Takotsubo syndrome [18], or chronic left ventricular dysfunction [9]. Components of left ventricular dysfunction include both reversible events such as myocardial stunning [19] and irreversible changes including myocyte loss and replacement fibrosis [11]. Animal studies with 12 week exposure to methamphetamine have not only shown cellular changes such as atrophy, hypertrophy, patchy cellular infiltration, and fibrosis, but have also demonstrated gradual recovery starting 3 weeks after cessation of exposure [11]. In patients, there are isolated case reports suggesting that methamphetamine associated cardiomyopathy is reversible with discontinuation of abuse $[8,9]$.

While the extent of fibrosis defined by LGE predicts recovery of left ventricular function in patients with coronary artery disease and myocardial infarction [16], there are insufficient data regarding functional recovery in patients with non-ischemic cardiomyopathy [20]. However, the extent of fibrosis in patients with non-ischemic cardiomyopathy, as identified by LGE, predicts event free survival [15].

\section{Conclusion}

In the specific case of this patient with methamphetamine-associated cardiomyopathy, the LGE study did not demonstrate any enhancement, consistent with an absence of significant fibrosis. Left ventricular function recovered with 6 months of medical therapy and decreased drug abuse. While it is unknown whether, in a larger cohort of patients, the absence or presence of CMR identified fibrosis would predict recovery, the benign LGE findings in this patient likely portended a favorable outcome. 


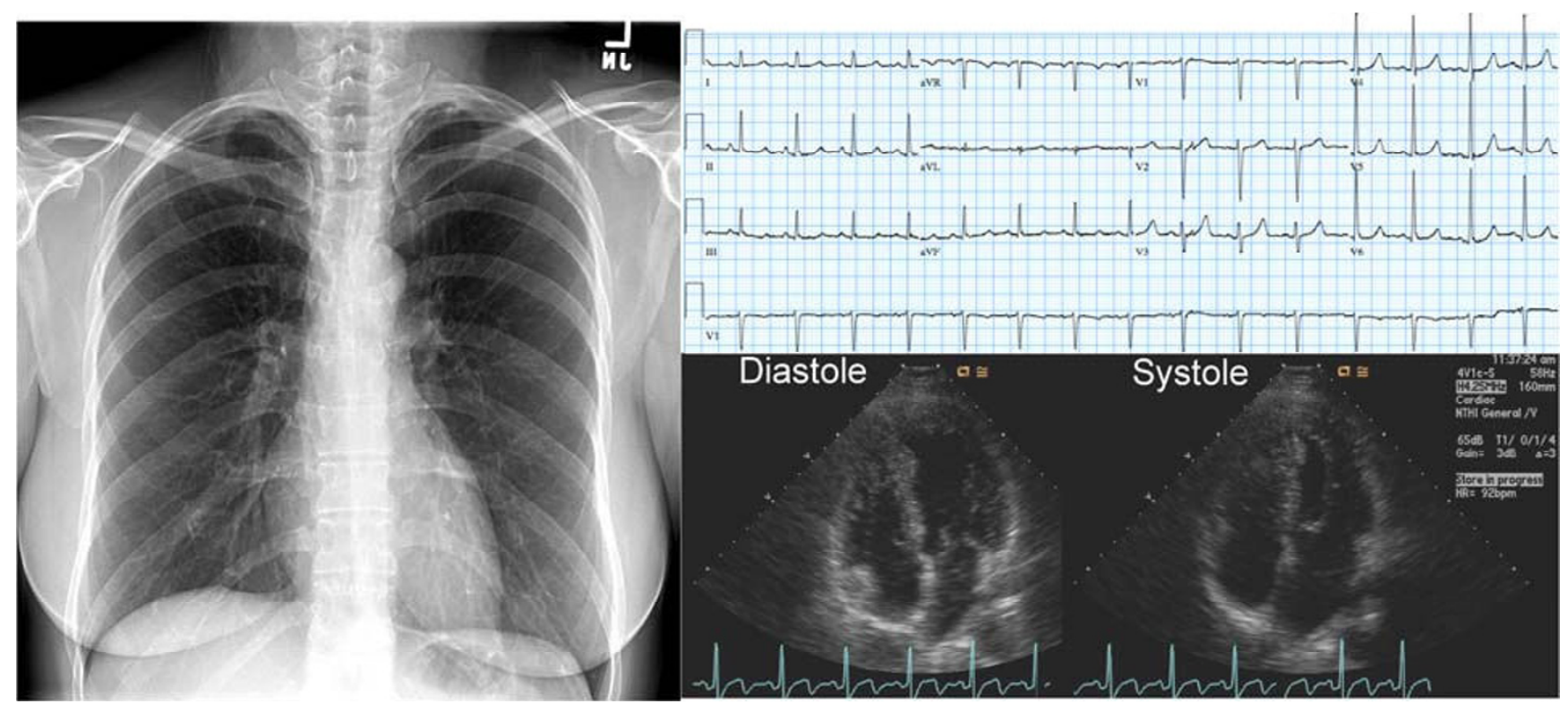

\section{Figure 3}

Chest X-ray, electrocardiogram, and 2D echocardiograms of the patient after 6 months of therapy. The cardiac silhouette is now normal, the ST-T changes on ECG have resolved, and the 2-D echocardiogram shows normal systolic function.

\section{Competing interests}

The authors declare that they have no competing interests.

\section{Authors' contributions}

JEL and SS analyzed the data and wrote the manuscript. KK and SS conceived of the study, and participated in its design and coordination. GC participated in the acquisition of the data. MB participated in the acquisition and analysis of the data. All authors read and approved the final manuscript.

\section{Consent}

Written informed consent was obtained from the patient for publication of this case report and accompanying images. A copy of the written consent is available for review by the Editor-in-Chief of this journal.

\section{Acknowledgements}

Magnetic resonance imaging support provided by a grant from the UC Davis Imaging Research Center.

\section{References}

I. Wolkoff DA: Methamphetamine abuse: an overview for health care professionals. Hawaii Med J 1997, 56:34-36.

2. Diercks DB, Fonarow GC, Kirk JD, Jois-Bilowich P, Hollander JE, Weber JE, Wynne J, Mills RM, Yancy C, Peacock WF: Illicit stimulant use in a United States heart failure population presenting to the emergency department (from the Acute Decompensated Heart Failure National Registry Emergency Module). Am J Cardiol 2008, 102:1216-1219.

3. Yeo KK, Wijetunga M, Ito H, Efird JT, Tay K, Seto TB, Alimineti K, Kimata C, Schatz IJ: The association of methamphetamine use and cardiomyopathy in young patients. Am J Med 2007, 120:165-171.
4. Karch SB, Stephens BG, Ho CH: Methamphetamine-related deaths in San Francisco: demographic, pathologic, and toxicologic profiles. J Forensic Sci 1999, 44:359-368.

5. Turnipseed SD, Richards JR, Kirk JD, Diercks DB, Amsterdam EA: Frequency of acute coronary syndrome in patients presenting to the emergency department with chest pain after methamphetamine use. J Emerg Med 2003, 24:369-373.

6. Wijetunga M, Bhan R, Lindsay J, Karch S: Acute coronary syndrome and crystal methamphetamine use: a case series. Hawaii Med I 2004, 63:8-13.

7. Srikanth S, Barua R, Ambrose J: Methamphetamine-associated acute left ventricular dysfunction: a variant of stress-induced cardiomyopathy. Cardiology 2008, 109:188-192.

8. Jacobs LJ: Reversible dilated cardiomyopathy induced by methamphetamine. Clin Cardiol 1989, 1 2:725-727.

9. Hong R, Matsuyama E, Nur K: Cardiomyopathy associated with the smoking of crystal methamphetamine. JAMA 1991, 265: II $152-1154$.

10. Maeno Y, Iwasa M, Inoue H, Koyama H, Matoba R: Methamphetamine induces an increase in cell size and reorganization of myofibrils in cultured adult rat cardiomyocytes. Int J Legal Med 2000, I I 3:20I-207.

II. Islam MN, Kuroki H, Hongcheng B, Ogura Y, Kawaguchi N, Onishi S, Wakasugi C: Cardiac lesions and their reversibility after long term administration of methamphetamine. Forensic Sci Int 1995, 75:29-43.

12. He SY, Matoba R, Fujitani N, Sodesaki K, Onishi S: Cardiac muscle lesions associated with chronic administration of methamphetamine in rats. Am J Forensic Med Pathol 1996, 17:155-162.

13. McCrohon JA, Moon JC, Prasad SK, McKenna WJ, Lorenz CH, Coats AJ, Pennell DJ: Differentiation of heart failure related to dilated cardiomyopathy and coronary artery disease using gadolinium-enhanced cardiovascular magnetic resonance. Circulation 2003, 108:54-59.

14. Mahrholdt H, Wagner A, Judd RM, Sechtem U, Kim RJ: Delayed enhancement cardiovascular magnetic resonance assessment of non-ischaemic cardiomyopathies. Eur Heart J 2005, 26: $|46|-\mid 474$.

15. Wu KC, Weiss RG, Thiemann DR, Kitagawa K, Schmidt A, Dalal D, Lai S, Bluemke DA, Gerstenblith G, Marban E, Tomaselli GF, Lima JA: Late gadolinium enhancement by cardiovascular magnetic 
resonance heralds an adverse prognosis in nonischemic cardiomyopathy. J Am Coll Cardiol 2008, 5 I :24I 4-242I.

16. Kim RJ, Wu E, Rafael A, Chen EL, Parker MA, Simonetti O, Klocke FJ, Bonow RO, Judd RM: The use of contrast-enhanced magnetic resonance imaging to identify reversible myocardial dysfunction. N Engl J Med 2000, 343: I 445-I 453.

17. Seiden LS, Sabol KE: Methamphetamine and methylenedioxymethamphetamine neurotoxicity: possible mechanisms of cell destruction. NIDA Res Monogr 1996, 163:25I-276.

18. Tamura A, Kawano Y, Watanabe T, Aso T, Abe Y, Yano S, Kadota J: A report of 2 cases of transient mid-ventricular ballooning. Int J Cardiol 2007, I 22:e I0-12.

19. Hernandez-Pampaloni M, Bax JJ, Morita K, Dutka DP, Camici PG: Incidence of stunned, hibernating and scarred myocardium in ischaemic cardiomyopathy. Eur J Nucl Med Mol Imaging 2005, 32:3|4-32I.

20. Bello D, Shah DJ, Farah GM, Di Luzio S, Parker M, Johnson MR, Cotts WG, Klocke FJ, Bonow RO, Judd RM, Gheorghiade M, Kim RJ: Gadolinium cardiovascular magnetic resonance predicts reversible myocardial dysfunction and remodeling in patients with heart failure undergoing beta-blocker therapy. Circulation 2003, 108:1945-1953

Publish with Biomed Central and every scientist can read your work free of charge

"BioMed Central will be the most significant development for disseminating the results of biomedical research in our lifetime. "

Sir Paul Nurse, Cancer Research UK

Your research papers will be:

- available free of charge to the entire biomedical community

- peer reviewed and published immediately upon acceptance

- cited in PubMed and archived on PubMed Central

- yours - you keep the copyright 